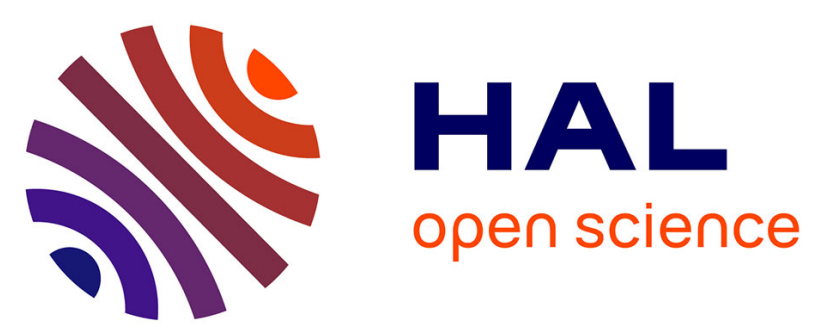

\title{
Trace metal fractionation as a mean to improve on the management of contaminated sediments from runoff water infiltration basins
}

\author{
Amelène El Mufleh, Béatrice Bechet, Anne Gaudin, Véronique Ruban
}

\section{To cite this version:}

Amelène El Mufleh, Béatrice Bechet, Anne Gaudin, Véronique Ruban. Trace metal fractionation as a mean to improve on the management of contaminated sediments from runoff water infiltration basins. Environmental Technology, 2013, 34 (10), pp.1255-1266. 10.1080/09593330.2012.745619 . hal-00989914

\section{HAL Id: hal-00989914 https://hal.science/hal-00989914}

Submitted on 12 May 2014

HAL is a multi-disciplinary open access archive for the deposit and dissemination of scientific research documents, whether they are published or not. The documents may come from teaching and research institutions in France or abroad, or from public or private research centers.
L'archive ouverte pluridisciplinaire HAL, est destinée au dépôt et à la diffusion de documents scientifiques de niveau recherche, publiés ou non, émanant des établissements d'enseignement et de recherche français ou étrangers, des laboratoires publics ou privés. 


\section{Trace metal fractionation as a mean to improve on the management of}

2 contaminated sediments from runoff water infiltration basins

4 Amelène El-Mufleh ${ }^{\mathrm{a}}$, Béatrice Béchet ${ }^{\mathrm{a}}$, Anne Gaudin ${ }^{\mathrm{b}}$, Véronique Ruban ${ }^{\mathrm{a}}$

5

12 Nantes Atlantique Universités, Nantes, France

13 e-mail : anne.gaudin@univ-nantes.fr

16 Corresponding author:

17 Béatrice BECHET

18 Beatrice.bechet@ifsttar.fr

19 Phone : +33(0)2 40845687

$20 \quad$ Fax : + $33(0) 240845998$ 


\section{Trace metal fractionation as a mean to improve on the management of contaminated sediments from runoff water infiltration basins}

The management of stormwater sediment is a key issue for local authorities due to their pollution load and important tonnages. In view of reuse, e.g. for embankment, the environmental evaluation of these highly aggregated sediments requires studying trace metals fractionation and mobility. The distribution of trace metals $(\mathrm{Cd}, \mathrm{Cr}, \mathrm{Cu}, \mathrm{Ni}, \mathrm{Pb}$, $\mathrm{Zn}$ ) and their level of lability in three French stormwater sediments was determined using sequential and kinetic extractions (EDTA reagent) associated with mineralogical analysis and SEM observations. Using microanalysis, new data were acquired on the evolution of aggregate state during extractions and on its significant role in trace metals retention. Trace metals were, in particular, observed to be very stable in small aggregates $(10-50 \mu \mathrm{m})$. The comparison of the two extraction methods pointed out that EDTA extraction was not convenient to evaluate the stable fraction of $\mathrm{Cr}$, $\mathrm{Ni}$ and $\mathrm{Zn}$. Moreover, the results were relevant for basins presenting similar trace metals sources, whatever the physicochemical conditions in basins. The results suggest that the management of stormwater sediments could be improve by a better knowledge of metal mobility, as far as chemical extractions could highlight the localisation of the mobile trace metals fraction. Treatment could be therefore avoided or specific treatment could be applied to a reduced volume of sediments.

Keywords: Urban stormwater sediment, Retention/infiltration basins, Trace metal fractionation, Microanalysis, Sediment management 
2 Retention and infiltration basins are widely used in urban stormwater management to provide 3 protection from flooding, recharge of aquifers and improvement of downstream waters 4 quality. Runoff waters collected in these basins may actually carry significant loads of 5 pollutants, present as soluble or particulate substances [1-3]. These basins are supposed to 6 accumulate large quantities of sediment over time by decantation and trap pollutants such as 7 trace metals, nutrients and PAHs [4;5]. After few years, clogging is frequently observed, modifying the infiltration ability account would appear necessary in order to maintain both

9 the hydraulic and depuration performance of these ponds. But the removal and disposal of residue represent a key issue for local authorities as far as estimates and surveys show that

11 tonnages are important and represent each year in France, several million tons of dry matter and in an agglomeration scale, tens of thousands of tons [6]. Due to their low organic matter content, their spreading on agricultural land is not recommended and landfill deposit or incineration is very costly. Treatment and/or reuse (e.g. for embankment) seem to be a right compromise. Thus the underlying question is about the sediments quality towards the impact on close environment, in particular towards the migration of pollutants. Consequently, a strong knowledge of the inherent characteristics of the materials is required. Among these characteristics, the mobility of associated pollutants to solid phases is strongly related to their speciation, defined as the distribution of an element amongst different chemical species in a system [7]. However, a direct determination of the speciation of an element is often not attainable, but in many cases, fractionation can provide useful information on release availability. Fractionation is defined as a process of classification of an analyte or group of analytes from a sample according to physical or chemical properties $[7 ; 8]$. Furthermore, the knowledge of the pollutants mobility within solid phases, could avoid treating the whole sediment. As no legislation for stormwater sediment management was produced until now, in 
particular standardized tests to verify the safety of these sediments, it could be convenient to use well known, referenced and fairly simple to implement methods to assess pollutants mobility and improve the treatment of the sediments.

Regarding metallic pollutants, sequential and kinetic extractions are the most widely used fractionation methods to assess the "operationally defined" distribution of metallic pollutants in the different solid phases of a material and to evaluate the potential mobility of these metals, respectively. A few studies using sequential extraction methods were carried out on basin sediments to study trace metal fractionation [9]. However, to our knowledge kinetic extractions were never carried out on basin sediments.

The objective of this study was to examine trace metals fractionation, in order to access to their potential mobility within physical phases. The methodology used is based on the comparison of sequential and kinetic extractions in order to define the fractionation of trace metals on the different solid phases of the sediments [10;11]. To support the results of extractions, mineralogical analysis (XRD) and microscopic observations (SEM-EDX) were performed to assess the nature of mineral phases of the sediments and to ensure the validity of the extraction protocols in terms of solid phase dissolution. The two chemical fractionation methods are compared in terms of performance of implementation and results, to provide managers with valuable information on the most convenient method in view of an optimal treatment of basin sediments.

\section{Materials and methods}

\subsection{Field sites and sediment sampling}

The sediments were sampled in three stormwater infiltration basins located in Nantes and Lens (respectively in the West and North of France). The first site selected for this study, i.e. Boisbonne basin, is located in the East of Nantes. The drained runoff waters come from a 
$16,000 \mathrm{~m}^{2}$ contribution area of the A11 highway. The average daily flow is about 27,000 vehicles. The Boisbonne basin was built in 1992 and had never been dredged since this date (figure 1(a)). The second basin, named Cheviré basin, is located South West of Nantes. It receives runoff waters from a $19,000 \mathrm{~m}^{2}$ contribution area of the southern part of the Cheviré bridge which is a section of the Nantes ring-road (figure 1(b)). Opened in 1991, the Cheviré bridge now carries an average daily flow of 90,000 vehicles. The third basin (G08), located in the industrial area of Lens, drains runoff waters from a 14,000 $\mathrm{m}^{2}$ contribution area of the A21 highway and carries an average daily flow of 80,000 vehicles (figure 1(c)). Since its opening in 1971, the basin had never been dredged. Specific zones are identified within each basin, based on both the uneven flow of water inside the basins and the development of vegetation (table 1). The entire surface of Cheviré and G08 basins is affected by infiltration of runoff waters, whereas the Boisbonne basin has a zone (BB1) remaining subaqueous (figure 1(a)). All infiltration zones are prone to changing redox conditions.

The samplings were performed in June 2009 for Boisbonne and Cheviré basins and in December 2009 for G08 basin. The sampled sediment layer can be distinguished from the underground soil by its black colour, its texture and its structure. The thickness of this layer ranges from a few centimeters to $30 \mathrm{~cm}$, depending on the zones. The sediment sampling was conducted on the whole thickness and on each zone of the three basins ( 3 zones for Boisbonne (figure 1(a)), 4 zones for Cheviré (figure 1(b)) and 4 zones for G08 basin (figure 1(c)) according to the frequency and speed of flooding in the different areas (table 1). For each zone, a representative sample was composed with an homogeneous mixture of 6 to 13 shots (depending on the size of each area) within a grid system distribution [12]. Only one representative sample of each zone was then analyzed. 


\subsection{Chemical and mineralogical sample characterization}

The $\mathrm{pH}$ value was measured in sediment/water suspensions (solid/liquid: 1/5 (V/V); NF ISO 10390 [13]) and using a TIM 900 (Radiometer Analytical TitraLab®) titration system. Total organic matter (TOM) content was determined by calcination at $550^{\circ} \mathrm{C}$ during 2 hours.

Total element contents, especially trace metal concentrations $(\mathrm{Cd}, \mathrm{Cr}, \mathrm{Cu}, \mathrm{Ni}, \mathrm{Pb}$ and $\mathrm{Zn}$ ) were determined on samples sieved to $2 \mathrm{~mm}$ and dried at $40^{\circ} \mathrm{C}$. The analyses were performed after mineralization of the samples by use of a mixture of $\mathrm{HF}$ and $\mathrm{HClO}_{4}$ acids (NF X 31-147 [14]). Analyses on a certified reference material BCR-320 (river sediment) were carried out to assess the quality of the analytical data. Determination of chemical element contents was performed by Inductively Coupled Plasma - Optical Emission Spectrometry (ICP-OES; Varian 720-ES). The quantification limits for $\mathrm{Cd}, \mathrm{Cr}, \mathrm{Cu}, \mathrm{Ni}, \mathrm{Pb}$ and $\mathrm{Zn}$ are respectively 0.5 , $5,2,10,10$ and $2 \mu \mathrm{g} . \mathrm{L}^{-1}$. In case of concentration under the limit of quantification, the sample was analyzed by Inductively Coupled Plasma - Mass Spectrometry (ICP-MS; Varian 820MS). The ICP-MS limit of quantification for trace elements is ranging from $0.02 \mu \mathrm{g} . \mathrm{L}^{-1}$ to $0.3 \mu \mathrm{g} . \mathrm{L}^{-1}$ depending on the element.

A Brüker "D8 Advance" powder diffractometer operating in Bragg-Brentano geometry $(\theta / 2 \theta)$ was used to identify the major crystalline phases by X-ray diffraction (XRD). This diffractometer is equipped with a copper anode and a germanium monochromator $\left(\mathrm{Cu}_{\mathrm{K \alpha} 1} \lambda=\right.$ $1.540598 \AA$ A) with a Vantec position sensitive detector. Diffractometer settings were $40 \mathrm{kV}, 40$ $\mathrm{mA}, 3.500-67.992^{\circ} 2 \theta$, step size $0.017^{\circ} 2 \theta$ and $1 \mathrm{~s}$ counting per step. The phase identification was performed using EVA software in conjunction with the Powder Diffraction File (PDF) database. The sediment samples were analysed by scanning electron microscopy (SEM) performed with a Hitachi S 570. Two observation modes are available: the imaging mode collecting low-energy secondary electrons to observe the surface topography of particles $\left(\mathrm{LaB}_{6}\right.$ tip, $30 \mathrm{kV}$ maximum), and Energy Dispersive $\mathrm{X}$-ray spectroscopy (EDX 
spectroscopy) analysis to get qualitative elemental composition between 1 and $10 \mathrm{keV}$ (limit of quantification $1000 \mathrm{ppm})$.

\subsection{Extraction procedures}

The sequential and kinetic extraction procedures were carried out on each zone of the three basins, Boisbonne (BB1 to BB3), Cheviré (CH1 to CH4) and G08 (G08z1 to G08z4). In order to verify which minerals dissolved during the extractions, XRD patterns were obtained prior to and after each extraction step of the sequential extraction and after $72 \mathrm{~h}$ of contact for kinetic extraction $[15 ; 16]$. The same samples were also characterized by SEM-observations. Metal analyses were performed using an ICP-OES and/or ICP-MS as described above.

\subsubsection{Sequential extraction}

Despite criticisms, sequential extractions have been frequently used for trace metal location in contaminated soils and in river and marine sediments [8]. The most widely applied method is derived from that proposed by Tessier et al. (1979) [17]. The European Community Bureau of Reference (BCR) has proposed an optimized three-step procedure, including an application for sediment with the production of Certified Reference Material $[18 ; 19]$. According to this procedure, the first extractable fraction, the exchangeable fraction, is related to clay, carbonates and amorphous phases, the second one is the reducible fraction related to metal (hydr)oxides and the third one is the oxidisable fraction related to organic matter. A fourth step was added consisting of mineralization of the final residue by use of a mixture of concentrated $\mathrm{HF} / \mathrm{HClO}_{4}$. This step is supposed to extract the residual fraction. The different steps are summarized in Table 2. The extraction procedure was conducted on $2 \mathrm{~g}$ dry sample (uncrushed and sieved to $2 \mathrm{~mm}$ ). The liquid-solid separation was performed by centrifugation and filtration of the supernatant on $0.45 \mu \mathrm{m}$ Millipore filter. Metal analysis was performed by ICP-OES and/or ICP-MS as described above (section 2.2). 
123 Blank tests were introduced in each series. $\mathrm{Cd}, \mathrm{Cr}, \mathrm{Cu}, \mathrm{Ni}$, and $\mathrm{Pb}$ concentrations of blank

124 samples were always below ICP-OES and ICP-MS quantification limits, Zn concentration is

125 lower than $0.01 \mathrm{mg} . \mathrm{L}^{-1}$ which is negligible by comparison to $\mathrm{Zn}$ concentration in the extracted

126 samples (over $10 \mathrm{mg} \cdot \mathrm{L}^{-1}$ ). The quality of the analyses was assessed by analyzing a reference

127 sediment BCR-527 (lake sediment), using the same procedure. A statistical test (two-sided $t$ -

128 test), used for significant differences from the reference content, confirmed that the 129 experimental values are not significantly different from the certified values $(\mathrm{P}>0.05)$, except 130 for copper, which is over estimated in step 1.

\section{$131 \quad$ 2.3.2 Kinetic extraction}

132 Kinetic extractions are also a widely used method to investigate kinetic aspects that 133 characterize the stability of the various trace metal-soil/sediment constituent association [20].

134 For a given agent, the kinetic extraction approach generates two kinds of data: (i) the 135 proportion of metal extracted with respect to the total metal content of sediment sample; (ii)

136 the kinetic behavior of metals. It has been suggested that kinetic extractions can be modeled

137 by two different pools. Although chemical extractants used for experiments do not perfectly

138 mimic natural conditions, the first pool of readily extracted metals, called "labile" [21], and 139 the second one of more slowly extracted metals, called "non labile", might be reasonably

140 attributed to potentially "mobile" and/or "bioavailable" metal pools [22]. In addition, the total

141 non-extractable fraction is defined as the difference between the total amount of metal in

142 sediment and the two above mentioned pools [23]. Several reagents are used for the kinetic

143 extractions but EthyleneDiamineTetraacetic Acid (EDTA), a well known strong chelating 144 agent, has been often used in soil studies for estimating the total extractable metal pool. As 145 EDTA is a non specific reagent, it was reported to remove organically bound metals as well 146 as those in oxides or secondary clay minerals [29]. This procedure was applied on various 
147 soils and river sediments to mimic mobility aspects of heavy metals but never on stormwater

148 infiltration pond sediments [11;21;23;24].

149 Kinetic extractions by EDTA were used on sediment samples to study :i) the maximal

150 potential metal extraction capacity after $72 \mathrm{~h}$; and ii) the extraction rates of metals released as

151 a function of time (between 0 and $72 \mathrm{~h}$ ). The EDTA kinetic extraction was conducted on dry

152 sample of each zone for the three basins (11 samples). For each zone, a series of $12 \times 1 \mathrm{~g}$

153 samples was mixed with $50 \mathrm{~mL}$ of $\mathrm{pH} 7$ solution of EDTA $(0.1 \mathrm{M})$ using a rotary stirrer for

15412 mixing periods (5, 15 and $30 \mathrm{~min} ; 1,2,4,8,16,24,36,48$ and $72 \mathrm{~h})$. The liquid-solid

155 separation was performed by centrifugation and filtration of the supernatant on a $0.45 \mu \mathrm{m}$

156 Millipore filter. A series of blank tests was added to the samples. The analysis of metals was

157 performed by ICP spectrometry as described above (section 2.2). As for sequential 158 extractions, the blank concentrations for trace metals are negligible.

159 The amount of each metal extracted for the mixing $t$ time was at first calculated (example in

160 figure 2(a)). Then the amount of metal extracted per solid weight unit (M) and the average

161 removal rate per time unit $\left(A_{M}(t)\right)$ are calculated. The evolution of $A_{M}(t)$ can generally be

162 described by two distinct linear segments representing two distinct pools and reacting with 163 two different kinetics (figure 2(b)). Three compartments associated with the two reaction rates

164 were defined: (i) the labile compartment $\mathrm{Q}_{\mathrm{L}}$, associated with a kinetic constant $\mathrm{k}_{\mathrm{L}}$, (ii) the 165 non-labile compartment $\mathrm{Q}_{\mathrm{NL}}$, associated with a kinetic constant $\mathrm{k}_{\mathrm{NL}}$ and (iii) the non166 extractable compartment $\mathrm{Q}_{\mathrm{NE}}$, obtained by subtracting $\mathrm{Q}_{\mathrm{L}}$ and $\mathrm{Q}_{\mathrm{NL}}$ of total amount of metal $167\left(\mathrm{Q}_{\mathrm{L}}+\mathrm{Q}_{\mathrm{NL}}+\mathrm{Q}_{\mathrm{NE}}=\right.$ total amount). Labanowski et al. (2008) [23] described in details the 168 general procedure of modeling and assessment of these three compartments.

\section{$170 \quad 3 . \quad$ Results and discussion}


172 SEM observations indicate that the three sediments are mainly composed of single particles

173 (figure 3(a)) and aggregates (figure 3(b)). The single particles are mainly primary minerals

174 identified by XRD: quartz, albite ( $\mathrm{Na}$ feldspar), microcline (K feldspar) and mica. Clay

175 mineral (peak at $14 \AA$ and $7 \AA$ ) occurs as a minor phase in Cheviré and G08 sediments. The

$176 \mathrm{XRD}$ analysis revealed the presence of an additional carbonate phase (calcite) in G08

177 sediments (figure 4 - untreated sample). The presence of these well crystallised mineral

178 phases is related to the nature of the soil beneath the basins and to the local geological

179 context, which controls the nature of the mineral particles in runoff waters. Sand constitutes

180 the bottom of the Nantes basins, the parent rock being micaschists. The G08 basin is located

181 in limestone formations. The aggregates have a size ranging from 10 to $300 \mu \mathrm{m}$ and are

182 composed of both the primary minerals and an organic binding phase. Such aggregates were

183 previously observed as dominant components in the sediment of an infiltration pond near

184 Lyon (France) [25].

185 The main chemical characteristics of the bulk samples are presented in Table 3. The 186 characteristics (pH, TOM, chemical content) of the Cheviré sediments are similar to those 187 reported in previous studies [26-28].

188 The higher concentrations of calcium (and probably magnesium) in G08 sediment by 189 comparison to Cheviré and Boisbonne sediments are related to the presence of calcite as 190 mineral phase. This carbonated phase is also responsible for the high $\mathrm{pH}$ value of G08 191 samples. In spite of similar organic matter (OM) contents, $\mathrm{pH}$ values for Cheviré and 192 Boisbonne sediments are quite different. This result could be explained by the nature of the 193 organic matter present in the sediments. As described in previous studies $[9 ; 25,29]$, the 194 organic matter of stormwater sediments is attributed to both natural and anthropogenic 195 contributions, related to the development of vegetation and to the nature of OM in runoff 196 waters. Anthropogenic organic matter may originate from oil and fuels as well as from 
vehicle and infrastructure corrosion (tire and road fragments) [30]. Neutral $\mathrm{pH}$ values are

198 reported in the literature [6]. Otherwise, Boisbonne $\mathrm{pH}$ values are in the range of those of 199 organic natural soil (around 5). This is relevant with the lower contamination of Boisbonne sediment, that should be related to a low amount of anthropogenic OM received. Unlike the 201 homogeneity in terms of mineralogical composition, the total organic matter (TOM \%) 202 contents are different from one area to another for Cheviré and Boisbonne basins. For G08, the distribution is fairly similar for the four areas. The highest TOM content is found within BB1, CH4 and G08-z3 zones located near the overflow outlet (figure 1). This observation is consistent with the results of previous study Cannavo et al. (2010) [28]. This result could be explained by the heterogeneity of the sedimentation process within the basins.

207 Trace metal contents are compared to the Dutch intervention thresholds [31], used as 208 reference. The thresholds are applied to a standard soil containing $25 \%$ clay $(<2 \mu \mathrm{m})$ and $10 \%$ 209 organic matter. So for each type of soil (different clay and/or organic matter content) 210 thresholds should be adjusted using two correction formulas [32]. According to these 211 corrected thresholds, G08 basin is the most contaminated basin. It is polluted with $\mathrm{Cd}$ and $\mathrm{Cr}$, 212 whereas $\mathrm{Cu}, \mathrm{Pb}$ and $\mathrm{Zn}$ concentrations are above the intervention value. Cheviré samples are 213 highly loaded with $\mathrm{Cu}, \mathrm{Pb}$ and $\mathrm{Zn}$, and concentrations are above the intervention thresholds 214 for $\mathrm{Cu}$ and $\mathrm{Zn}$. Boisbonne samples are the less polluted with trace metals. This basin is 215 polluted with $\mathrm{Cd}$ (only $\mathrm{BB} 1$ ), $\mathrm{Cu}, \mathrm{Ni}$ and $\mathrm{Zn}$ but concentrations never exceed the intervention 216 thresholds. The differences in trace metal content can be explained by the age of the basins 217 (G08 is the older), the traffic, the atmospheric contribution, the mineralogy and the $\mathrm{pH}$ values, 218 knowing that a low $\mathrm{pH}$ favors trace metal leaching. No trace metal $(\mathrm{Zn}$ or $\mathrm{Pb})$ was detected by 219 EDX-spectroscopy within samples containing $\mathrm{Pb}$ and $\mathrm{Zn}$ concentrations above $1000 \mathrm{mg} \cdot \mathrm{kg}^{-1}$. 220 This result may be attributed to the heterogeneity of trace metal distribution within the sample 221 and to the high aggregation state. 


\subsection{Sequential extraction}

223 Results of trace metal fractionation obtained by sequential extractions for the three basins are 224 presented in figure 5. Results are expressed in percent of the total content, in the four 225 operationally defined fractions. For a given element, the mass balance was calculated by 226 dividing the sum of concentrations from the four extraction steps by the total concentration measured on bulk sediment. The balances were in the range 78 to $100 \%$ (figure 5). The recovery is over $82 \%$ for $83 \%$ of the trials. The lower recovery rates could be related to the aqueous washing between two extraction steps and to losses of matter due to spattering reaction of samples when adding $\mathrm{H}_{2} \mathrm{O}_{2}$ (step 3), leading to an under-estimate of trace metal amounts bound to organic matter or very stable mineral phases.

Trace metal distribution. The results show that inside a same basin, the partitioning of trace metals between the different fractions is quite homogeneous with a standard deviation of less than $20 \%$ in $70 \%$ of the cases. In order to synthesise the results thereafter, only data from one representative area are presented for each basin: $\mathrm{BB} 2$ for Boisbonne, $\mathrm{CH} 4$ for Cheviré and G08z2 for G08 (figure 5).

The results of sequential extractions clearly suggest that the fractionation of trace metals in Cheviré sediment was always more similar to those of G08 sediment than Boisbonne sediment. Fractionation of elements such as $\mathrm{Cd}, \mathrm{Cr}$ and $\mathrm{Ni}$ was close for the three basins:

240 exchangeable $\mathrm{Cd}$ accounted for 55 to $66 \%$ and large amounts of $\mathrm{Cr}$ and $\mathrm{Ni}(50-75 \%)$ 241 remained in the residual fraction, except for $\mathrm{Ni}$ in Boisbonne sediment which is equally 242 distributed among exchangeable and residual fractions. $\mathrm{Cu}$ and $\mathrm{Pb}$ of Cheviré and $\mathrm{G} 08$ basins 243 are predominantly bound to metallic hydr(oxides) and organic matter, whereas most Zn was 244 released by step 1 and 2 (exchangeable Zn, weakly complexed Zn, Zn bound to hydr(oxides)). 245 The results for the Boisbonne sediment show that substantial amounts of $\mathrm{Cu}, \mathrm{Pb}$ and $\mathrm{Zn}(30$ to $24640 \%$ ) remained also in residual fractions. The differences between Cheviré/G08 and Boisbonne sediments are attributed to the variation of trace metals speciation in sediments 
due to the nature of organic matter, ratio between geochemical background and anthropogenic 249 contamination and low $\mathrm{pH}$ of the sediment.

250 The results of sequential extractions for the Chevire sediment are consistent with previous 251 studies [9,33], except for lead which was more released from the oxidisable fraction of the 252 sediment sampled in 2001 (40\% against 27\% (this study)). Before 2000 in France, the main 253 sources of lead in road environment were leaded gasoline, brake linings and deicing salts [34]. 254 Since the removal of lead from fuels, the lead species contained in automobile exhausts 255 disappeared in runoff waters. It was shown that $\mathrm{Pb}$ (originally labile in gas combustion) was 256 rapidly transformed into particulate and non-labile forms [30]. One can suggest that these 257 specific forms of lead, which don't exist anymore, were released from oxidisable fraction 258 (step 3 of sequential extraction procedure) of sediment sampled a few years around 2000.

$259 \mathrm{Cr}, \mathrm{Cu}, \mathrm{Ni}, \mathrm{Pb}$ and $\mathrm{Zn}$ distribution was studies by sequential extraction among lake sediments 260 [15], those materials being characterized by the same mineralogical composition than the 261 sediments of the basins (except for calcite). The distribution of $\mathrm{Cu}, \mathrm{Pb}$ and $\mathrm{Zn}$ among the 262 operationally-defined fractions is very similar to those observed for Cheviré, G08 and 263 especially Boisbonne. This underlines again the more natural character of the organic matter 264 of the latter basin. On the other hand, the comparison of our results with those of sediments 265 contaminated by $\mathrm{Pb}-\mathrm{Zn}$ mining is much less easy [16]. In this later study, $\mathrm{Pb}$ was 266 predominantly bound to (hydr)oxides (reducible fraction) but remained also in the residual 267 fractions. $\mathrm{Zn}$ is partly in the exchangeable fraction but principally distributed among the 268 oxidisable and residual fractions. The speciation of heavy metals acquired during their 269 emission has therefore a very strong impact on their later mobility.

270 XRD and SEM study. The XRD analyses and SEM observations of samples after each step of 271 sequential extractions were very similar for the 3 basins. A representative diffractogram of 272 G08z2 sample illustrates the general XRD results (figure 4). The XRD method used in this 
study does not allow quantitative analyses, thus it is only possible to conclude about the presence or not of the crystallised minerals. The main mineral phases i.e., quartz, feldspar, mica and clay were recovered in the samples obtained after each step of the sequential extractions. This indicates that there is no or non distinguishable (by this method) dissolution of these primary minerals which could compromise the interpretation of the results on metals fractionation. Calcite (peak at $3 \AA$ ) is completely dissolved within step 1 of the sequential extractions. Therefore trace metals bound to this solid phase are entirely solubilised. The first three residues of sequential extraction were observed by SEM. As for bulk samples, no trace metal was analysed with EDX-spectroscopy. After the first and the second steps of the sequential extraction, single mineral particles appear to be damaged. This degradation could result from the effect of the reagent or from the frictional effects during stirring. By contrast, the aggregates have the same morphology (size, shape) and composition as before the extraction procedure (figure 3(b)). However, after the third step, the aggregates are partly destroyed or broken, leading to finer aggregates mostly sized from 10 to $50 \mu \mathrm{m}$. This observation is consistent with the work on stormwater infiltration sediment from Lyon [25], which shows that $\mathrm{H}_{2} \mathrm{O}_{2}$ damages the larger aggregates of an infiltration pond sediment with a resulting size decrease (\%D50 from 55 to $10 \mu \mathrm{m}$ ). This means that the removal of the organic matter partly destroys the aggregates and that OM plays a significant role as binding phase in aggregates. Furthermore, small aggregates are still observed after each step. It means that these aggregates play a significant role in the retention of trace metals located in the oxidisable (related to organic matter) and residual fractions. Indeed, $\mathrm{Cu}$ and $\mathrm{Pb}$ were highly released during step 3, as the aggregates were partly destroyed by oxidation of the organic matter. In the residual fraction, trace metals such as $\mathrm{Cr}$ and $\mathrm{Ni}$, which are not solubilised by the reagents of the first three steps, are strongly stabilized in aggregates. Due to the disaggregation of some of the aggregates during steps 3 and 4, one could have expected to 
observe higher metal concentrations on solid phases (at least in the case of $\mathrm{Zn}$ ). However, no trace metal was analysed by EDX-spectroscopy, confirming that the trace metals are highly concentrated on a few particles, which location and observation are difficult due to a 301 heterogeneous distribution in the sediments.

\subsection{Kinetic extraction}

303 Results of trace metal fractionation obtained by kinetic extractions for the three basins are 304 presented in figure 5. Results are expressed in percent of the total content, in the three compartments $\left(\mathrm{Q}_{\mathrm{L}}, \mathrm{Q}_{\mathrm{NL}}\right.$ and $\left.\mathrm{Q}_{\mathrm{NE}}\right)$ of the kinetic extractions. The sum of $\mathrm{Q}_{\mathrm{L}}+\mathrm{Q}_{\mathrm{NL}}+\mathrm{Q}_{\mathrm{NE}}$ is normally $100 \%$. In figure 5 , some recoveries are over $100 \%$, particularly for $\mathrm{Cu}$, the main 307 explanation is that $\mathrm{Q}_{\mathrm{L}}$ compartment is overestimated by the method.

308 Trace metal distribution. As for sequential extraction procedure, inside a same basin, the 309 partitioning of trace metals between the different compartments is homogeneous (standard 310 deviation less than $30 \%$ in $86 \%$ of the cases, excluding $\mathrm{Cd}$ and $\mathrm{Q}_{\mathrm{NE}}$ compartment). As for 311 sequential extraction, only data from one representative area are presented for each basin 312 (BB2, CH4 and G08z2) (figure 5).

313 The distribution of trace metals between labile, non labile and non extractable compartments 314 could be summarized as follows: $\mathrm{Cd}, \mathrm{Cu}, \mathrm{Pb}$ and $\mathrm{Zn}$ (only for Boisbonne basin) are highly 315 labile; $\mathrm{Cr}$ and $\mathrm{Ni}$ (for Cheviré and G08 basins) are clearly non extractable; and Zn from 316 Cheviré and G08 basins is fairly distributed between the three compartments. Kinetic 317 extractions have never been achieved on sediments from runoff water infiltration basins. The 318 comparison of our results with weakly contaminated river sediments [11] does not show the 319 same behavior of $\mathrm{Cd}, \mathrm{Cu}, \mathrm{Pb}$ and $\mathrm{Zn}$ between $\mathrm{Q}_{\mathrm{L}}, \mathrm{Q}_{\mathrm{NL}}$ and $\mathrm{Q}_{\mathrm{NE}}$ compartments. On the other 320 hand, $\mathrm{Cd}, \mathrm{Pb}$ and $\mathrm{Zn}$ distributions between the three compartments in a contaminated soil 321 mimic our results [23]. 
XRD and SEM study. As for sequential extractions, the XRD analyses and SEM observations

323 of samples after kinetic extractions were very similar for the 3 basins. The XRD pattern of the residue after $72 \mathrm{~h}$ of contact with EDTA for zone 2 from G08 basin (G08z2) is presented in that there is no or few dissolution of minerals. As for the sequential extraction residue, calcite 327 (peak at $3 \AA$ ) is almost completely dissolved thereby solubilising trace metals bound to this 328 phase. No trace metal was detected by EDX-spectroscopy within the residues after $72 \mathrm{~h}$ of contact with EDTA. The SEM observations highlight that the residues are similar to the

330 untreated samples, with a slight damage to the minerals (single particles). We can deduce 331 from these latest observations that the damage on the minerals, observed for the residues after 332 sequential extraction steps, was mainly due to the reagent effects and not to stirring effects. 333 Moreover, as for sequential extraction steps, aggregates (10 to $300 \mu \mathrm{m})$ are still observed after $33472 \mathrm{~h}$ of contact with EDTA. This result confirmed the important role of aggregates belonging 335 to the non-extractable compartment, in the retention of trace metals. Trace metals in the non336 extractable compartment were not solubilised by EDTA indicating a strong stabilization in 337 aggregates.

\section{$338 \quad 3.4 \quad$ Comparison of trace metal fractionation}

339 The comparison of the two extraction procedures aimed at highlighting the complementarity 340 of the two methods in describing trace metal fractionation. Indeed, despite the shortcomings 341 of the sequential extraction method including incomplete dissolution of target phases, 342 incomplete removal of dissolved species due to readsorption or reprecipitation, (according to 343 trace metals adsorption/desorption properties), the comparison of both the fractionations 344 allows to draw some trends.

345 The comparison of the two extraction methods highlights that: 
- Cd from exchangeable and reducible fractions appears to be labile, whereas $\mathrm{Cd}$ contained in

347 the residual and oxidisable fractions (for G08) is non labile. The fractionation of chromium is

348 homogenous throughout all the sediments: residual and oxidisable fractions are the bearing-

349 phases of the non extractable chromium.

350 - Regarding copper, results of sequential and kinetic extractions are hardly compared. The 351 high complexation capacity of $\mathrm{Cu}$ with EDTA could be responsible for its strong lability and 352 explain the discrepancy between both extractions.

353 - a large part of nickel is labile (52\%) and the remaining is largely non extractable (57\%).

354 However, the comparison between sequential and kinetic extractions leads to the same 355 comment for the three basins, i.e., nickel from the exchangeable fraction is labile, the 356 reducible fraction is non labile and $\mathrm{Ni}$ from the oxidisable and residual fractions is non 357 extractable.

358 - Lead from the exchangeable and reducible fractions is labile, $\mathrm{Pb}$ from the oxidisable fraction 359 is non labile and $\mathrm{Pb}$ from the residual fraction is non extractable.

360 - and that $\mathrm{Zn}$ from the exchangeable fraction is labile, that from the reducible fraction is non

361 labile and that from the oxidisable and residual fractions is non extractable.

362 Thus it can be drawn that: i) trace metals from the exchangeable fractions are always labile, 363 whereas those from the residual fraction are non extractable; ii) the reducible fraction 364 corresponds to labile or non labile compartments; iii) and the oxidisable or organic matter 365 fraction seems to correspond to the non labile or non extractable compartments. In terms of 366 bounding strength between trace metals and solid surfaces, trace metals are strongly adsorbed 367 on organic phases (oxidisable fraction) or tightly included in the residual fraction as revealed 368 by the level of extraction from the non labile or the non extractable compartments. $\mathrm{Cd}, \mathrm{Cr}, \mathrm{Cu}$ 369 and $\mathrm{Pb}$ are weakly adsorbed on metal oxides (reducible fraction), whereas $\mathrm{Ni}$ and $\mathrm{Zn}$ are 370 strongly adsorbed on metal oxides. Complexation data from the literature indicate the 
371 following order of affinity between EDTA and metallic ions: $\mathrm{Cu}>\mathrm{Ni}>\mathrm{Pb}>\mathrm{Zn}$. Trace metals,

372 such as $\mathrm{Cu}, \mathrm{Pb}$ and $\mathrm{Zn}$ are in fact quantified in the labile compartment but it is not the case for

373 Ni. As $\mathrm{Ni}$ was largely non-extractible, one can outline the main role of the speciation

374 (chemical form) of trace metals in runoff waters on their mobility capacity within the

375 sediment.

\subsection{Findings summary}

Aggregation and extraction efficiency. Decidedly, the most unexpected result of this study

is the documentation of the evolution of aggregate state within the extraction steps and their role in the retention of trace metals. Previous studies have suggested that sequential extraction procedures are not perfectly selective with respect to mineral dissolution, and without quantitative XRD, the minerals that dissolve with each successive extraction are operationally defined [15]. In this study, we showed that not only isolated mineral phases but also aggregates (depending on their disintegration state) contribute to trace metal mobilization. SEM observations gave essential information that could not be obtained by XRD. However, it would be necessary to use complementary techniques to assess the dissolution of amorphous 386 or poorly crystallised metallic oxides and hydroxides.

Moreover, this study underlines that a part of trace metals is really stabilized in aggregates (small aggregates $(10-50 \mu \mathrm{m})$ ). Therefore, if the partitioning of the stable aggregates from the instable and single particles could be achieved, it would be possible to reuse the sediments

390 after the sole treatment of the non aggregated fraction and thus reduce the treatment costs.

391 Is kinetic extraction a convenient method to quantify heavy metal potential mobility?

392 One of the objectives of this study was to assess the relevance of a simple method such as 393 EDTA extraction to optimize sediment treatment. The results showed that metallic pollutants 394 are distributed among two categories: i) copper, cadmium and lead, which have a low EDTA 395 non extractable fraction; ii) chromium, nickel and zinc present in oxidizable and residual 
fractions which are non EDTA extractable. For $\mathrm{Cu}$ and $\mathrm{Pb}$, the use of EDTA extraction

397 appears to be relevant. It will give a rough under estimate of stable amounts of metals. For

$398 \mathrm{Cd}$, it is difficult to conclude from the results of this study. For $\mathrm{Cr}, \mathrm{Ni}$ and $\mathrm{Zn}$, the use of

399 EDTA extraction over estimates the very stable metal fraction, as the oxidizable fraction was

400 included. As the degradation of OM, a major constituent of sediment aggregates which can be

401 strongly modified by drying, remoisting or biological degradation is likely to release trace

402 metals, the EDTA extraction could not be considered as a convenient method to evaluate the 403 stable fraction of $\mathrm{Cr}, \mathrm{Ni}$ and $\mathrm{Zn}$.

404 It would be interesting, in the case of stormwater sediments, to compare these kinetic 405 extractions results with leaching tests representative of natural conditions. This will assess the 406 relevance of: i) the kinetic extractions method and ii) the extractant used. Such comparisons 407 were conducted on contaminated soils [23]. The findings of the study indicate that EDTA 408 extractions provide an indication for the maximum potential metal extractability, helpful for 409 the prediction of long-term risks.

410 Can these conclusions be applied to all stormwater sediments? This study shows that 411 metals have a rather similar behaviour from one basin to the other, indicating that the 412 chemical extraction used seems to overcome physicochemical conditions such as $\mathrm{pH}$ or redox 413 conditions (for BB1 subaqueous area). However, in natural conditions, $\mathrm{pH}$ and redox 414 conditions are recognized to highly influence metal speciation and stability. It raises the 415 question of trace metal sources. For these three road basins, the sources are quite similar.

416 How can these conclusions guide manager's decisions? The comparison between 417 sequential and kinetic extractions has provided information on trace metals fractionation and 418 stability within stormwater sediments. The coupling of these procedures with XRD analyses 419 and SEM observations has highlighted that organic matter plays a significant role as binding 420 phase in aggregates and underlined the influence of aggregates in the retention of trace metals. 
421 As this approach is new for stormwater sediments, a validation of these results is necessary.

422 Kinetic extraction results should be confronted to leaching tests representative of natural conditions to predict long-term risks and trace metal fractionation could be compared to the distribution of these same trace metals in fractions obtained by physical fractionation of sediment solid phases, as density fractionation. After validation, these methods will allow to access quickly and easily to information on trace metal distribution and their stability within stormwater sediments. The localization of the metals will permit to treat only the fractions containing the labile trace metals. Information on trace metals stability will allow the reuse of the whole or the non-treated part of the sediment. In this case, additional physicochemical characteristics should be known i) $\mathrm{pH}$ and redox conditions and ii) TOM contents (to evaluate aggregation state).

\section{Conclusion}

434 In this paper we used several indirect and direct techniques to characterize the trace metal 435 fractionation in sediments from runoff water infiltration basins. Our objective was to access to 436 trace metal potential mobility within physical phases as a mean to improve the management 437 of stormwater sediments.

438 The comparison of sequential and kinetic extractions shows that trace metals from the exchangeable fraction are always labile, whereas those from the residual fraction are non extractable. Trace metals associated to the reducible fraction are labile or non labile, whereas

441 those bound to organic matter (oxidisable fraction) are non labile or non extractable. The 442 coupling of these procedures with XRD analyses and SEM observations has allowed: i) to 443 ensure the slight or non-dissolution of mineral phases (except calcite); ii) to highlight that 444 organic matter plays a significant role as binding phase in aggregates and iii) to underline the 
445 influence of aggregates in the retention of trace metals, especially a remaining fraction of very 446 stable small aggregates was observed.

447 One single method is not sufficient to explain the fractionation and the mobility of trace 448 metals in the different fractions and this study highlighted the complementarity of the two 449 extraction methods for a better understanding of trace metal distribution among solid phases. 450 This methodology could serve as a tool for a better assessment of trace metal behaviour for 451 the management of sediment from stormwater infiltration basins. Several methods have been 452 proposed for the treatment of stormwater sediments; among the recent ones sieving coupled 453 with attrition has proved quite efficient. The decision to treat sediment is based on bulk 454 concentration determination; however, a better knowledge of metal mobility, as proposed in 455 this study, might be useful. In case the metals of concern appear not to be mobile (e.g. 456 localized in the residual fraction), treatment could be avoided, hence saving money. 


\section{Acknowledgements}

2

3 This work benefits from the financial support of the "Région des Pays de la Loire" in the

4 framework of the research project POLESUR "Soil and water pollution in urban areas" (2008-

5 2011). 


\section{REFERENCES}

[2] Béchet B, Durin B, Legret M, Le Cloirec P. Size fractionation of heavy metals in highway runoff waters. In: Rauch S, Morrison GM, Monzon A, editors. Highway and Urban Environment. Paris: Alliance for global sustainability bookseries 17, Springer; 2010. p. 235-243.

[3] Crabtree B, Moy F, Whitehead M, Roe A. Monitoring pollutants in highway runoff. Water Environ. J. 2006; 20 (4) : 287-294.

[4] Sansalone JJ, Buchberger SG. Partitioning and first flush of metals and solids in urban highway runoff. J. Environ. Eng. 1997; 123: 134-43.

[5] Lee PK, Touray JC, Baillif P, Ildefonse JP. Heavy metal contamination of settling particles in a retention pond along the A-71 motorway in Sologne, France. Sci. Tot. Env. 1997; 201: 1-15.

[6] Marsalek J, Watt WE, Anderson BC. Trace metal levels in sediments deposited in urban stormwater management facilities. Water Sci. Technol. 2006; 53(2): 175-83.

[7] European Commission Directive 2000/60/EC of the European Parliament and of the Council establishing a framework for the Community action in the field of water policy, JO L327 du 22.12.2000.

[8] Ruban V. Caractérisation et gestion des sédiments de l'assainissement pluvial. EG19. Paris : Laboratoire Central des Ponts et Chaussées DISTC ; 2005.

[9] Epandage des boues issues du traitement des eaux usées, French Decree n97-1133 (December 8,1997).

[10] Pétavy F, Ruban V, Conil P. Attrition efficiency in the decontamination of stormwater sediments. Appl. Geochem. 2009; 24: 153-61.

[11] Yousef YA, Hvitved-Jacobsen T, Sloat J, Lindeman W. Sediment accumulation in detention or retention ponds. Sci. Tot. Env 1994, 146-147: 451-56. 
[12] Templeton DM, Ariese F, Cornelis R, Danielsson LG, Muntau H, Van Leeuwen HP, Lobinski R. Guidelines for terms related to chemical speciation and fractionation of elements. Definitions, structural aspects, and méthodological approaches (IUPAC Recommandations). Pure and Appl. Chem., 2000, 72(8), 1453-1470.

[13] Cornu S, Clozel B. Extractions séquentielles et spéciation des éléments trace métalliques dans les sols naturels. Analyse critique. Etude et Gestion des sols 2000 ; 7(3) 179-189.

[14] Durand C. Caractérisation physico-chimique des produits de l'assainissement pluvial. Origine et devenir des métaux traces et des polluants organiques. Poitiers University (France); 2003.

[15] Cornu S, Montagne D, Conil P. Comparaison d'extractions séquentielles et cinétiques pour la spéciation de As dans des sols sableux contaminés. C. R. Geoscience $2004 ; 336: 1007-15$.

[16] Gismera MJ, Lacal J, Silva P, García R, Sevilla MT, Procopio JR. Study of metal fractionation in river sediments. A comparison between kinetic and sequential extraction procedures. Environ. Pollut. 2004; 127: 175-82.

[17] Hébrard-Labit C. Recommandations pratiques pour la gestion des produits de l'assainissement pluvial. Guide technique LCPC. Paris : Laboratoire Central des Ponts et Chaussées DISTC ; 2006.

[18] AFNOR. Soil quality - Soils, sediments - Determination of pH. NF ISO 10390. Paris, 2005.

[19] AFNOR. Soil quality - Soils, sediments - Total solubilizing by acid attack. NF X 31 147. Paris, 1996. 
[20] Ryan PC, Wall AJ, Hillier S, Clark L. Insights into sequential chemical extraction procedures from quantitative XRD: a study of trace metal partitioning in sediments related to frog malformities. Chem. Geol. 2002; 184: 337-57.

[21] Cappuyns V, Swennen R, Niclaes M. Application of the BCR sequential extraction scheme to dredged pond sediments contaminated by Pb-Zn mining: A combined geochemical and mineralogical approach. J. Geochem. Explor. 2007 ; 93: 78-90.

[22] Tessier A, Campell P, Bisson M.. Sequential extractions procedure for the speciation of particulate trace metals. Anal. Chem. 1979 ; 51: 844-51.

[23] Quevauviller P, Ure A, Muntau H, Griepink B. Improvement of analytical measurements within the BCR programme: single and sequential extraction procedures applied to soil and sediment analysis. Int. J. Environ. Anal. Chem. 1993; 51 : 129-34.

[24] Rauret G, Lopez-Sanchez JF, Sahuquillo A, Rubio R, Davidson C, Ure A, Quevauviller P. Improvement of the BCR 3-step extraction procedure prior to the certification of new sediment and soil reference materials. J. Environ. Monit. 1999 ; 1 : $57-61$.

[25] Bermond A, Yousfi I, Ghestem JP. Kinetic approach to the chemical speciation of trace metals in soils. Analyst 1998; 123: 785-89.

[26] Fangueiro D, Bermond A, Santos E, Carapuça H, Duarte A. Kinetic approach to heavy metal mobilization assessment in sediments: choose of kinetic equations and models to achieve maximum information. Talanta 2005; 66: 844-57.

[27] Bermond A, Varrault G, Sappin-Didier V, Mench M. A kinetic approach to predict soil trace metal bioavailability: preliminary results. Plant Soil 2005; 275: 21-9.

[28] Labanowski J, Monna F, Bermond A, Cambier P, Fernandez C, Lamy I, Van Oort F. Kinetic extractions to assess mobilization of $\mathrm{Zn}, \mathrm{Pb}, \mathrm{Cu}$ and $\mathrm{Cd}$ in a metalcontaminated soil : EDTA vs. citrate. Environ. Pollut. 2008; 152: 693-701. 
[29] Irene M, Lo C, Yang XY. EDTA extraction of heavy metals from different soil fractions and synthetic soils. Water, Air, Soil Pollut. 1999; 109: 219 - 36.

[30] Badin AL, Méderel G, Béchet B, Borschneck D, Delolme C. Study of the aggregation of the surface layer of Technosols from stormwater infiltration basins using grain size analyses with laser diffractometry. Geoderma 2009; 153,: 163-71.

[31] Legret M., Le Marc C., Demare D. et Colandini. Pollution par les métaux lourds dans un bassin de décantation recevant des eaux de ruissellement d'origine routière. Environ. Technol., 1995 ; 16, 1049-1060.

[32] Durin B, Béchet B, Legret M, Le Cloirec P. Influence of infiltration flowrate on trace elements mobilisation from an infiltration basin sediment. La Houille Blanche $2007 ; 5: 120-26$.

[33] Cannavo P, Vidal-Beaudet L, Béchet B, Lassabatère L, Charpentier S. Spatial distribution of sediments and transfer properties in soils in a stormwater infiltration basin. J. Soil Sediment 2010; 10(8), 1499-1509.

[34] Coulon A, El-Mufleh A, Cannavo P, Vidal-Beaudet L, Béchet B, Charpentier S. Specific stability of organic matter in a stormwater infiltration basin. J. Soil Sediment to be published

[35] Clozel B, Ruban V, Durand C, Conil P. Origin and mobility of heavy metals in contaminated sediments from retention and infiltration ponds. Appl. Geochem. 2006; $21: 1781-98$.

[36] Ministry of Housing, Spatial Planning and Environment. Intervention Values and Target Values - Soil Quality Standards. The Hague (the Netherlands): DirectorateGeneral for Environmental Protection; 1994, 19 p. 
[37] Spierenburg A, Demanze C. Pollution des sols: Comparaison - application de la liste néerlandaise. Environnement \& Technologie 1995; 146 : 79-81.

[38] Durand C, Ruban V, Amblès A. Mobility of trace metals in retention pond sediment. Environ. Technol. 2004; 25: 881-88.

[39] Legret M, Pagotto C. Evaluation of pollutant loadings in the runoff waters from a major rural highway. Sci. Tot. Env. 1999; 235: 145-50. 


\section{FIGURES CAPTIONS}

Figure 1 Schemes of a) Boisbonne, b) Cheviré and c) G08 basins

Figure 2 Evolution in time of $\mathrm{Ni}$ : a) extracted amount, b) removal rate for $\mathrm{G} 08 \mathrm{z} 2$ sample

Figure 3 SEM observations: Cheviré zone 4 ( $\mathrm{CH} 4)$ : a) mica particle (x 800) ;b) an aggregate (x 1100) - G08 zone 2 (G08z2)

Figure 4 XRD analysis of a G08 sample (zone 2) after the different sequential extraction steps and $72 \mathrm{~h}$ of contact with EDTA. $\mathrm{C}=$ clay, $\mathrm{M}=$ mica, $\mathrm{F}=$ feldspar, $\mathrm{Q}=$ quartz and Cal. $=$ calcite .

Figure 5 Distribution of trace metals between sequential extraction fractions (left) and between kinetic extractions compartments (right) for Boisbonne (B-SE and B-KE), Cheviré (C-SE and C-KE) and G08 (G-SE and G-KE) basins: a) Cd, b) Cr, c) Cu , d) $\mathrm{Ni}, \mathrm{e}) \mathrm{Pb}$ and f) $\mathrm{Zn}$ 
Table 1 Characteristics of the basin zones

\begin{tabular}{llll}
\hline Basin & Zone & Flow & Vegetation \\
\hline Boisbonne & BB1 & Perennially subaqueous & Floating plants \\
& BB2 & Permanent water supply with variable flow (drainage and surface runoff) & Herbaceous \\
& BB3 & Intermittent, related to rain events (only road runoff) & Herbaceous and reeds \\
\hline Cheviré & CH1 & Turbulence zone & Only brumbles \\
& CH2 & Major flood zone & Herbaceous \\
& CH3 & Raised zone & Herbaceous and shurbs \\
& CH4 & Slow sedimentation zone & Herbaceous and rush \\
\hline \multirow{2}{*}{ G08 } & Z1 to Z4 & Same flow conditions across the whole surface & Herbaceous \\
\hline
\end{tabular}




\section{Table 2 Sequential extraction procedure}

\begin{tabular}{|c|c|c|c|c|}
\hline Step & Reagent & Operating conditions & Fraction & $\overline{\text { Extracted phase }}$ \\
\hline 1 & $80 \mathrm{~mL}$ of $0.11 \mathrm{M}$ acetic acid & Stirred $16 \mathrm{~h}$ at ambient temperature & Exchangeable & $\overline{\text { Acid-soluble and exchar }}$ \\
\hline 2 & $\begin{array}{l}80 \mathrm{~mL} \text { of } 0.1 \mathrm{M} \text { hydroxylamine } \\
\text { hydrochloride }(\mathrm{pH} 2)\end{array}$ & Stirred $16 \mathrm{~h}$ at ambient temperature & Reducible & Fe and Mn oxides \\
\hline 3 & $\begin{array}{l}2 \times 20 \mathrm{ml} \text { of } 8.8 \mathrm{M} \mathrm{H} 2 \mathrm{O} 2 \\
100 \mathrm{~mL} \text { of } 1 \mathrm{M} \text { ammonium acetate }(\mathrm{pH} 2)\end{array}$ & $\begin{array}{l}1 \mathrm{~h} \text { at ambient temperature and } 1 \mathrm{~h} \text { at } 85^{\circ} \mathrm{C} \\
\text { Stirred } 16 \mathrm{~h} \text { at ambient temperature }\end{array}$ & Oxidisable & Organic matter \\
\hline 4 & Concentrated $\mathrm{HF} / \mathrm{HClO} 4$ & After calcination at $450^{\circ} \mathrm{C}$ & Residual & Residual \\
\hline
\end{tabular}


Table 3 Main physicochemical characteristics of the three sediments

\begin{tabular}{|c|c|c|c|c|c|c|c|c|c|c|c|}
\hline & \multirow{2}{*}{$\begin{array}{c}\mathrm{TOM}^{*} \\
(\%)\end{array}$} & \multirow{2}{*}{$\begin{array}{c}\mathrm{pH} \\
\text { (in water) }\end{array}$} & \multirow{2}{*}{$\begin{array}{c}\mathrm{Ca} \\
\left(\mathrm{g} \cdot \mathrm{kg}^{-1}\right)\end{array}$} & \multirow{2}{*}{$\begin{array}{c}\mathrm{Mg} \\
\left(\mathrm{g} \cdot \mathrm{kg}^{-1}\right)\end{array}$} & \multicolumn{6}{|c|}{ Trace metals contents $\left(\mathrm{mg} \cdot \mathrm{kg}^{-1}\right)$} \\
\hline & & & & & & $\mathrm{Cd}$ & $\mathrm{Cr}$ & $\mathrm{Cu}$ & $\mathrm{Ni}$ & $\mathrm{Pb}$ & $\mathrm{Zn}$ \\
\hline \multicolumn{12}{|c|}{ Boisbonne } \\
\hline & BB1 & 17 & 5.2 & 3.8 & 5.3 & 1.2 & 54 & 59 & 75 & 41 & 480 \\
\hline & BB2 & 9 & 4.4 & 2.2 & 3.3 & 0.4 & 43 & 27 & 34 & 32 & 132 \\
\hline & BB3 & 16 & 4.8 & 3.5 & 4.7 & 0.4 & 54 & 30 & 39 & 31 & 139 \\
\hline \multicolumn{12}{|l|}{ Cheviré } \\
\hline & $\mathrm{CH} 1$ & 7 & 7.5 & 18.0 & 6.0 & 0.5 & 48 & 190 & 20 & 70 & 784 \\
\hline & $\mathrm{CH} 2$ & 11 & 6.9 & 10.0 & 7.1 & 0.8 & 74 & 335 & 30 & 152 & 1274 \\
\hline & $\mathrm{CH} 3$ & 12 & 6.7 & 9.7 & 7.8 & 0.9 & 79 & 320 & 32 & 250 & 1714 \\
\hline & $\mathrm{CH} 4$ & 16 & 6.3 & 10.0 & 8.9 & 1.2 & 92 & 366 & 37 & 368 & 1863 \\
\hline \multicolumn{12}{|l|}{ G08 } \\
\hline & G08_z1 & 17 & 8.0 & 42.5 & 9.4 & 9.3 & 120 & 498 & 56 & 1130 & 2574 \\
\hline & G08_z2 & 17 & 8.2 & 48.7 & 9.5 & 9.6 & 111 & 489 & 54 & 1064 & 2587 \\
\hline & G08_z3 & 18 & 7.8 & 52.9 & 9.3 & 9.1 & 129 & 514 & 53 & 1099 & 2508 \\
\hline & G08_z4 & 16 & 7.8 & 46.0 & 9.3 & 9.2 & 112 & 457 & 54 & 1235 & 2595 \\
\hline \multicolumn{12}{|c|}{ Dutch standard (reference) } \\
\hline \multicolumn{6}{|c|}{ Polluted soil ${ }^{(1)}$} & 0.8 & 100 & 36 & 35 & 85 & 140 \\
\hline \multicolumn{6}{|c|}{ Intervention threshold $^{(2)}$} & 12 & 380 & 190 & 210 & 530 & 720 \\
\hline
\end{tabular}

* Total organic matter; ${ }^{(1)}$ Value at which a soil is considered contaminated; ${ }^{(2)}$ Value at which intervention is necessary [35] 